University of Nebraska - Lincoln

DigitalCommons@University of Nebraska - Lincoln

2012

\title{
Effects of Arterial Strain and Stress in the Prediction of Restenosis Risk: Computer Modeling of Stent Trials
}

\author{
Shijia Zhao \\ University of Nebraska-Lincoln, s-szhao3@unl.edu \\ Linxia Gu \\ University of Nebraska-Lincoln, gul@fit.edu \\ Stacey R. Froemming \\ Children's Hospital \& Medical Center, Omaha, NE
}

Follow this and additional works at: https://digitalcommons.unl.edu/mechengfacpub

Part of the Circulatory and Respiratory Physiology Commons, Equipment and Supplies Commons, Hematology Commons, and the Surgical Procedures, Operative Commons

Zhao, Shijia; Gu, Linxia; and Froemming, Stacey R., "Effects of Arterial Strain and Stress in the Prediction of Restenosis Risk: Computer Modeling of Stent Trials" (2012). Mechanical \& Materials Engineering Faculty Publications. 87.

https://digitalcommons.unl.edu/mechengfacpub/87

This Article is brought to you for free and open access by the Mechanical \& Materials Engineering, Department of at DigitalCommons@University of Nebraska - Lincoln. It has been accepted for inclusion in Mechanical \& Materials Engineering Faculty Publications by an authorized administrator of DigitalCommons@University of Nebraska Lincoln. 


\title{
Effects of Arterial Strain and Stress in the Prediction of Restenosis Risk: Computer Modeling of Stent Trials
}

\author{
Shijia Zhao, ${ }^{1}$ Linxia Gu, ${ }^{1,2}$ and Stacey R. Froemming ${ }^{3}$ \\ 1. Department of Mechanical and Materials Engineering, University of Nebraska-Lincoln, Lincoln, NE 68588-0656 \\ 2. Nebraska Center for Materials and Nanoscience, Lincoln, NE 68588-0656 \\ 3. Hybrid Catheterization \& Electrophysiology Laboratory, Children's Hospital \& Medical Center, Omaha, NE 68114-4133 \\ Corresponding author - Linxia Gu, email lgu2@unl.edu
}

\begin{abstract}
Purpose - In-stenting restenosis is one of the major complications after stenting. Clinical trials of various stent designs have reported different restenosis rates. However, quantitative correlation between stent features and restenosis statistics is scant. In this work, it is hypothesized that stress concentrations on arterial wall caused artery injury, which initiates restenosis. The goal is to assess the correlation between stent-induced arterial stress and strain and the documented restenosis rates.

Methods - Six commercially available stents, including balloon-expandable stents and self-expanding stents, were virtually implanted into the arteries through finite element method. The resulted peak Von Mises stress, principal stress, principal logarithm strain, as well as percentage of intimal area with abnormal higher stress were monitored.

Results - Positive correlation between arterial stress and strain after stent implantations and the documented restenosis rates from the corresponding clinical trials was found regardless of stent types. No statistical significant difference was observed for various stress or strain parameters serving as indicators of artery injury.

Conclusions - In-stent restenosis are less likely to occur as arterial mechanics are least altered by stent implantations. Optimization of stent designs to minimize the stent-induced arterial stresses and strains can reduce the arterial injury, and thus reduce the occurrence of restenosis. This work improved our understanding of the stent-lesion interactions that regulate arterial mechanics and demonstrated that arterial stress and strain could predict the risk of instent restenosis.
\end{abstract}

Keywords: Stent, Restenosis, Correlation, Stress, Strain, Finite element

\section{Introduction}

Stents have been used as scaffold to open the occluded arteries and restore the blood flow. The major drawback associated with stent implantation is restenosis, i.e. renarrowing of the transversal section of the artery. Clinical trials have reported various restenosis rates on different stent designs. The vessle with a diameter being less than $3 \mathrm{~mm}$, the presence of residual stenosis at the end of procedure, lesion characterization as well as the length of stent were identified as the predictors of restenosis $[1,2]$. It has also been speculated that stent design features contribute to the inflammatory response and injury on arterial wall which led to the development of restenosis [3-5]. Recently, Timmins et al. has compared two stent designs using the porcine model, and stated that higher arterial stress caused by one stent design provoke more arterial injury, resulting in the augmented neointimal thickening [6]. In addition to numerous clinical studies, computational methods have been widely used to study the impact of stent deployment on the arterial mechanics [7-11]. Since the stent-induced arterial stress or strain is a local parameter integrating the stent design features with lesion properties, it was associated with the level of arterial injury, and could serve as a unique comprehensive index factor for the restenosis. However, quantitative correlation between stent induced stress or strain parameters and the documented restenosis is scant.

In this study, it is hypothesized that stent-induced stress or strain on the artery wall could predict the oc- 
currences of restenosis. Six clinical trials were investigated, and six corresponding stent designs including balloon-expandable and self-expanding stents were implanted into stenosed arteries through finite element (FE) method. Numerical simulations were used to mimic the stenting procedure and assess the stress on the arterial wall after stent implantations. The correlations between mechanical parameters on the artery wall and the documented restenosis rates were then quantified.

\section{Materials and Methods}

Six commercial stents were considered including five balloon-expandable stents (PS, Express, S670, Multilink Vision and Driver stent), and one self-expanding stent (GPS carotid stent). The 3-D finite element models of these stents were shown in Figure 1. The physical parameters of these stents were tabulated in Table 1. The PS, Express, and S670 stents were made of 316L stainless steel with mechanical properties defined by Young's modulus $E=190 \mathrm{GPa}$, Poisson ratio $v=0.3$, and Yield stress $\sigma_{Y}=207 \mathrm{MPa}$. The Multilink Vision and Driver stents were made of L605 Cobalt Chromium alloy with material parameters as Young's modulus $E=243 \mathrm{GPa}$, Poisson ratio $v=0.3$, and Yield stress $\sigma_{\mathrm{Y}}=500 \mathrm{MPa}$. The inelastic behavior of balloon-expandable stents was assumed as a perfect plasticity material model. The GPS carotid stent was made of Nitinol, whose non-linear superelasticity was adopted as a predefined user material to include the stress induced phase transformation between the austenite and martensite phases [12].

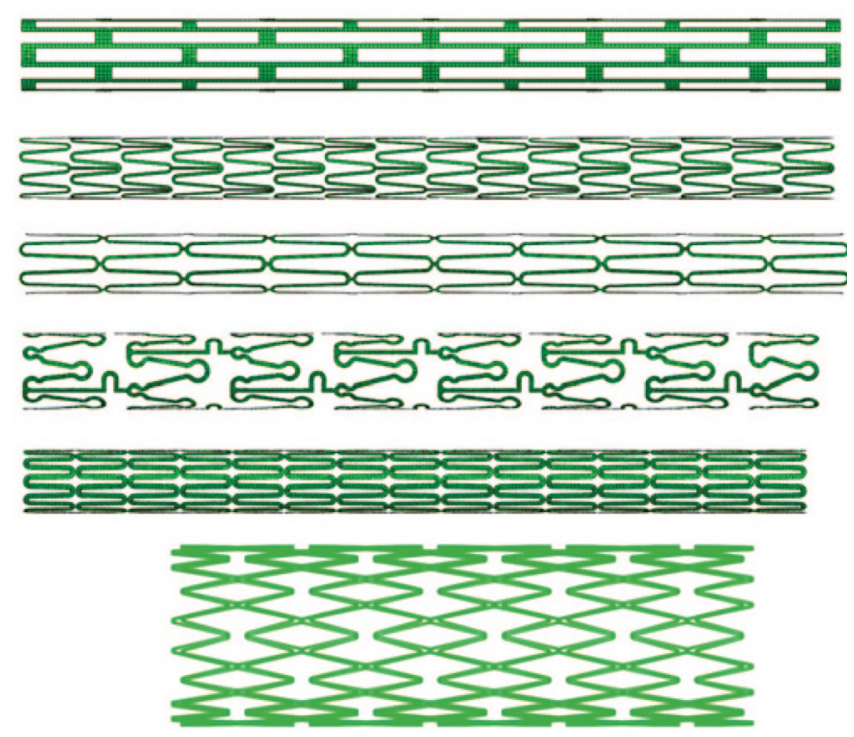

Figure 1. Computational models of six stents (from top to bottom): PS stent, Express stent, S670 stent, Multilink Vision stent, Driver stent, and GPS carotid stent.
The PS stent at the disease lesion location just before its expansion was depicted in Figure 2. Considering the symmetry of the whole PS stenting system, only onehalf in both circumferential and axial directions were analyzed. Based on the clinical trials of balloon-expandable stents, the artery was generalized as a straight hollow cylinder with length of $26 \mathrm{~mm}$, inner diameter of 3 $\mathrm{mm}$ and uniform thickness of $0.75 \mathrm{~mm}$. For the self-expanding GPS stent only, the targeted carotid artery was averaged with an inner diameter of $9 \mathrm{~mm}$ and thickness of $1 \mathrm{~mm}$. The plaque was generalized as parabolic profile with length of $13 \mathrm{~mm}$ along longitudinal direction and circular profile with an edge ratio of 2:1 at its narrowest lumen for all cases. This asymmetric plaque could lead to a remaining lumen diameter of $30 \%$ of the reference lumen, which is referred to as $70 \%$ stenosis, as in the case of PS stent [13], or 50\% for all other cases [14-18]. The material behaviors of artery and plaque were described using hyperelastic constitutive models with the non-zero material coefficients as $C_{10}=0.019513$ $\mathrm{MPa}, C_{03}=0.02976 \mathrm{MPa}$ for the artery; and $C_{10}=0.04 \mathrm{MPa}$, $C_{02}=0.003 \mathrm{MPa}, C_{03}=0.02976 \mathrm{MPa}$ for the plaque [19]. The mesh convergence study was conducted on the finite element model for the PS stenting system. The element sizes of $0.12 \mathrm{~mm}$ for plaque and $0.14 \mathrm{~mm}$ for the artery were adopted as the relative error between meshes is $0.77 \%$ in terms of the maximum Von Mises (VM) stress on artery. The artery wall and plaque were discretized into 18400 and 8910 C3D8RH elements, respectively.

Table 1. Physical parameters of six stents.

\begin{tabular}{lrrr}
\hline & Length & $\begin{array}{r}\text { Outer } \\
\text { diameter }\end{array}$ & $\begin{array}{r}\text { Strut } \\
\text { thickness }\end{array}$ \\
\hline $\begin{array}{c}\text { Palmaz-Schatz stent } \\
\text { (Johnson \& Johnson) }\end{array}$ & $16 \mathrm{~mm}$ & $3.0 \mathrm{~mm}$ & $0.09 \mathrm{~mm}$ \\
$\begin{array}{c}\text { Express Stent } \\
\text { (Boston Scientific) }\end{array}$ & $16 \mathrm{~mm}$ & $3.0 \mathrm{~mm}$ & $0.13 \mathrm{~mm}$ \\
$\begin{array}{c}\text { S670 stent } \\
\text { (Medtronic) }\end{array}$ & $16.62 \mathrm{~mm}$ & $3.0 \mathrm{~mm}$ & $0.13 \mathrm{~mm}$ \\
$\begin{array}{c}\text { Multilink Vision stent } \\
\text { (Guidant) }\end{array}$ & $15.34 \mathrm{~mm}$ & $3.0 \mathrm{~mm}$ & $0.08 \mathrm{~mm}$ \\
$\begin{array}{c}\text { Driver stent } \\
\text { (Medtronic) }\end{array}$ & $15 \mathrm{~mm}$ & $3.0 \mathrm{~mm}$ & $0.09 \mathrm{~mm}$ \\
$\begin{array}{l}\text { GPS Carotid stent } \\
\text { (ev3) }\end{array}$ & $20 \mathrm{~mm}$ & $10 \mathrm{~mm}$ & $0.22 \mathrm{~mm}$ \\
\hline
\end{tabular}

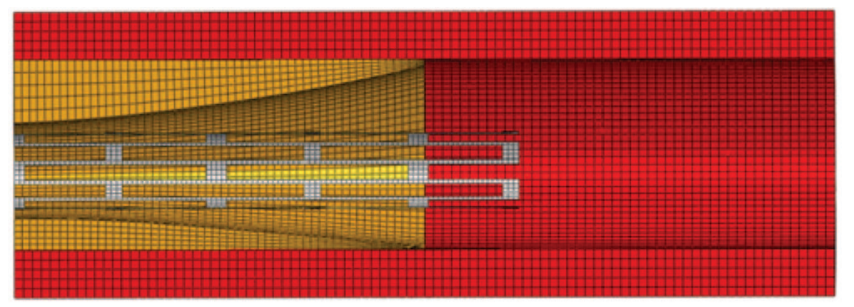

Figure 2. The three-dimensional finite element model of the PS stenting system. 
Non-linear large deformation analyses were performed using the commercial finite element codeAbaqus (Dassault Systèmes Simulia Corp., Providence, RI, USA). Both ends of the artery were constrained in the axial direction to mimic a long artery. No relative sliding was allowed at the interface between the plaque and artery wall. Uniform displacement was used to mimic the balloon expansion until the final diameter of the stent reach $3 \mathrm{~mm}$. For the self-expanding GPS stent, a uniform displacement was used to crimp it into a sheath, and then the stent expanded automatically after the sheath slide off. A frictionless finite sliding surface-tosurface contact between stent and diseased lesion was assumed. These conditions used to mimic the stenting procedure have been validated by our previous invitro experiments $[8,20]$.

The correlation between the obtained arterial stress or strain parameters (data set $x$ ) and the documented re- stenosis rates (data set $y$ ) was quantified by the Pearson correlation coefficient $r$ as defined as follows:

$$
r=\frac{\operatorname{Cov}(x, y)}{S x * S y}=\frac{\frac{1}{n-1} \sum_{i=1}^{n}\left(x_{i}-\bar{x}\right) *\left(y_{i}-\bar{y}\right)}{\sqrt{\frac{1}{n-1} \sum_{i=1}^{n}\left(x_{i}-\bar{x}\right)^{2}} * \sqrt{\frac{1}{n-1} \sum_{i=1}^{n}\left(y_{i}-\bar{y}\right)^{2}}}
$$

where $\operatorname{Cov}(x, y)$ denotes the sample covariance between data sets $x$ and $y$, while $S x$ and $S y$ represent the standard deviations of $x$ and $y$, respectively.

\section{Results and Discussions}

When stents were expanded to push lesion outwards, the mechanical environments of artery wall were dra-

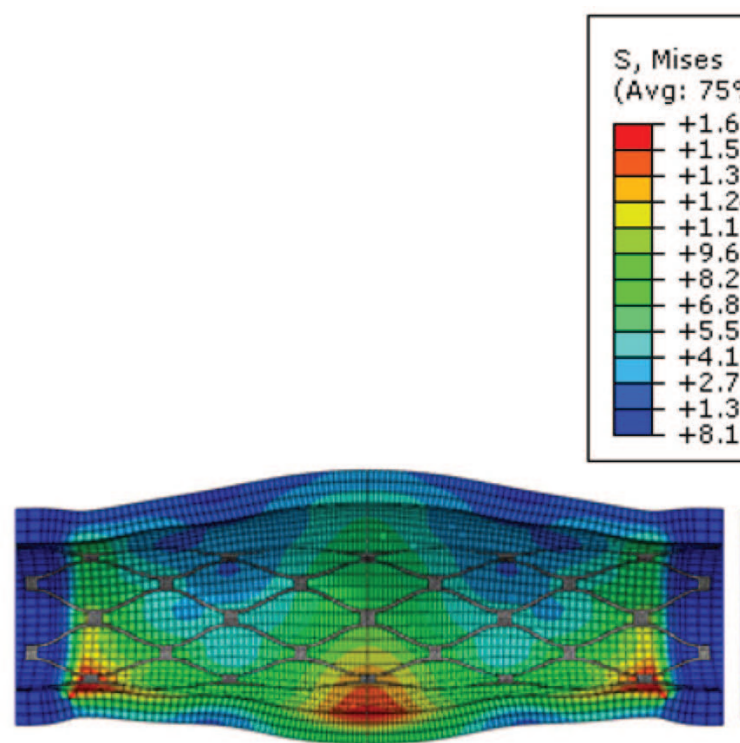

a

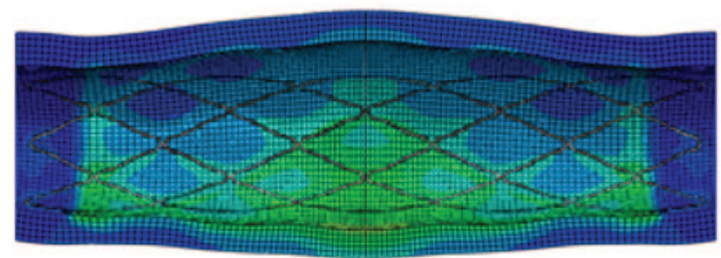

C

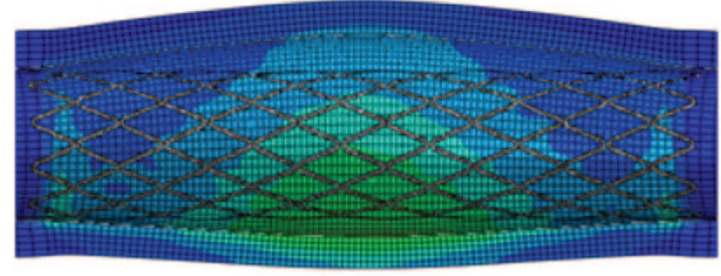

e

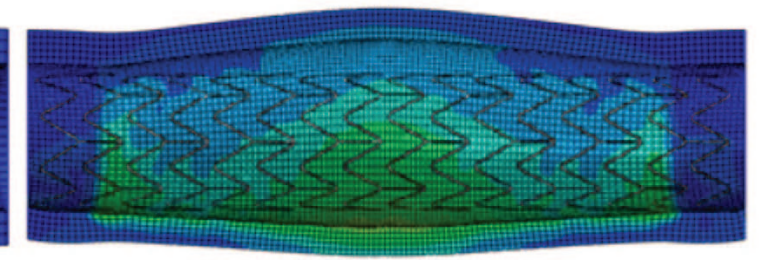

b



d

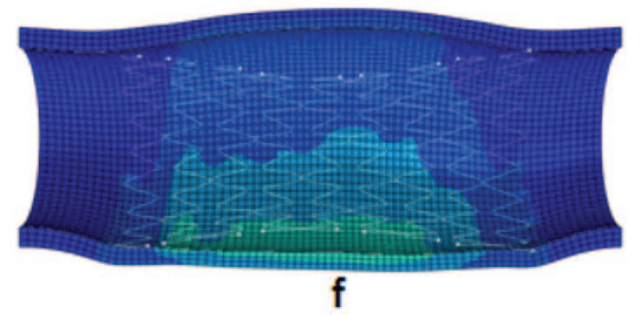

Figure 3. The Von Mises stress distributions on arterial wall induced by the implantation of various stents: (a) PS, (b) Express, (c) S670, (d) Multilink Vision, (e) Driver, and (f) GPS carotid stent. 
matically changed. Figure 3 showed the stent-induced VM stress distributions on arterial wall for all six types of stents. The stress concentration were consistently found on the artery section contacting with the thinner plaque side, indicating that the thicker plaque might serve as cushion to alleviate the arterial stress after stent implantation. The peak VM stresses on the artery wall are $0.165 \mathrm{MPa}, 0.112 \mathrm{MPa}, 0.107 \mathrm{MPa}, 0.108 \mathrm{MPa}, 0.092$ $\mathrm{MPa}$ and $0.054 \mathrm{MPa}$ for PS, Express, S670, Multilink Vision, Driver and GPS carotid stent, respectively. The peak principal logarithm strain (LE), as shown in Figure 4 , are $0.469,0.421,0.413,0.405,0.402$, and 0.312 for PS, Express, S670, Multilink Vision, Driver and GPS carotid stent, respectively. It was clearly demonstrated that different stent designs induced different levels of arterial stress and strain concentrations. Specifically, the conventional stainless steel Express and S670 stents induced larger strain on arterial wall than the cobalt chromium Multilink vision and Driver stents. This could be explained by the higher stiffness of cobalt chromium al- loy and the corresponding thinner strut, as listed in Table 1. It is consistent with the clinical observations on the role of strut thickness [21-23]. The GPS carotid stent induced less arterial stress and strain, which might be attributed to the lower stiffness of Nitinol, as demonstrated by Migliavacca et al [19].

The obtained arterial stress or strain parameters, including the maximum VM stresses, the maximum principal stresses, the maximum principal LEs, the percentages of intimal area where the VM stress exceeds 0.06 $\mathrm{MPa}$, along with the documented restenosis rates from clinical trials, were summarized in Table 2. The correlation between various arterial stress or strain parameters and the documented restenosis rates is quantified as the Pearson correlation coefficient using Equation (1), which was listed at the last row of Table 2. Specifically, a correlation coefficient between the restenosis rates and the maximum VM stresses was obtained as $0.979(p<0.012$, 95\% confidence interval: 0.814 to 0.998 ), which indicates that there is a significant and positive association be-

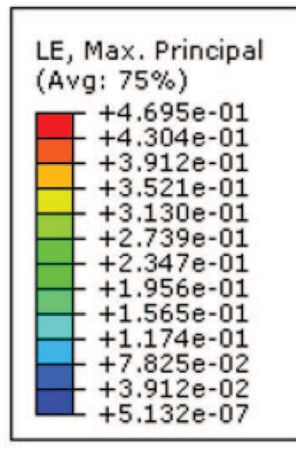

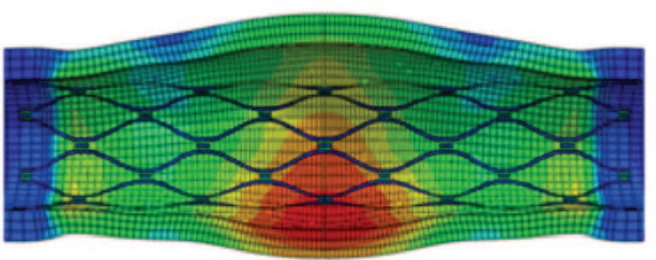

a

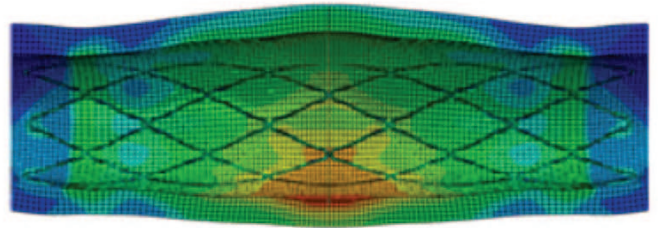

C

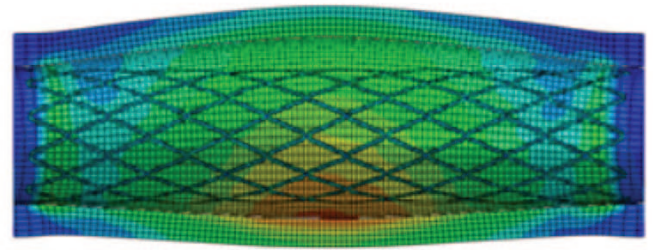

e

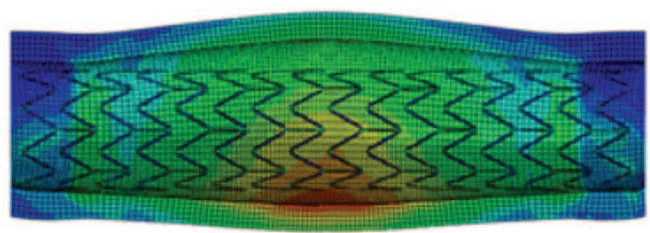

b



d

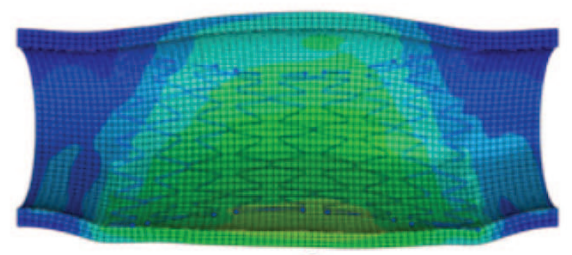

f

Figure 4. The principal logarithm strain distribution on arterial wall induced by the implantation of various stents: (a) PS, (b) Express, (c) S670, (d) Multilink Vision, (e) Driver, and (f) GPS carotid stent. 
Table 2. The correlation between the documented restenosis rates and the stent-induced stress or strain parameters.

\begin{tabular}{lrrrrr}
\hline Stent & $\begin{array}{r}\text { Restenosis } \\
\text { rate }\end{array}$ & $\begin{array}{r}\text { Maximum } \\
\text { VM Stress }\end{array}$ & $\begin{array}{r}\text { Maximum } \\
\text { Principal Stress }\end{array}$ & $\begin{array}{r}\text { Maximum } \\
\text { Principal LE }\end{array}$ & $\begin{array}{r}\text { Percentage of intimal area } \\
\text { (VM stress>0.06 MPa) }\end{array}$ \\
\hline PS & $31.60 \%[13]$ & $0.165 \mathrm{MPa}$ & $0.216 \mathrm{MPa}$ & 0.469 & $26.74 \%$ \\
Express & $19 \%[14]$ & $0.112 \mathrm{MPa}$ & $0.123 \mathrm{MPa}$ & 0.421 & $14.45 \%$ \\
S670 & $20.60 \%[15]$ & $0.107 \mathrm{MPa}$ & $0.106 \mathrm{MPa}$ & 0.413 & $11.82 \%$ \\
Multilink Vision & $15.74[16]$ & $0.108 \mathrm{MPa}$ & $0.096 \mathrm{MPa}$ & 0.405 & $11.38 \%$ \\
Driver & $15.66 \%[17]$ & $0.092 \mathrm{MPa}$ & $0.084 \mathrm{MPa}$ & 0.402 & $6.69 \%$ \\
GPS carotid & $6.84 \%[18]$ & $0.054 \mathrm{MPa}$ & $0.052 \mathrm{MPa}$ & 0.312 & $0 \%$ \\
Correlation coefficient & & $\mathrm{r}_{1}=0.979$ & $\mathrm{r}_{2}=0.964$ & $\mathrm{r}_{3}=0.945$ & $\mathrm{r}_{4}=0.973$ \\
& & & & & \\
\hline
\end{tabular}

tween the two data sets. This validated our hypothesis that stress concentrations on arterial wall caused artery injury, such as the denudation, and abnormal stretch of the intima, which initiates restenosis [24]. It implies that the stress concentration could serve as a unique indicator of arterial injury. A new stent design with minimal alteration of the arterial stresses could potentially reduce the occurrence of restenosis.

It is clear that all these stress or strain parameters have positive correlation with the documented restenosis rates. A Z-test was conducted to determine whether the injury indicator of the maximum VM stress is the same as the indicator of maximum principal LE at the level of $\alpha=0.05$. The calculated results indicated that there is no significant difference between the two correlation coefficients at the significance level of 0.05 . Thus, no statistical significant difference is obtained for all the listed stress or strain parameters serving as indicators of artery injury.

\section{Conclusions}

The injury of arterial wall induced by the interaction between stent and stenosed artery was considered as one of the important causes for the initiation of restenosis. This work simulated six clinical trials to quantify the relationship between stent-induced stress and strain parameters on the arterial wall and the documented instent restenosis rates. The virtual deployments of six stents including balloon-expandable and self-expanding stents in stenotic arteries were used to mimic the corresponding clinical trials. The correlation between the calculated arterial stress or strain parameters and the documented restenosis rates were then quantified. A positive correlation between arterial mechanics and restenosis rate was observed in this work. This is consistent with the recent in-vivo observations in porcine models [6]. It should be noted that the simulation of stent implantation in this study do not completely reflect all the attributes of the reported clinical trials. Various stent sizes in terms of diameter and length with the same unit structure were used in the clinical trials. Considering that stent is usually oversized by $5-15 \%$ greater than its reference artery, as well as the same unit configuration, one specific size of the stent model in this work was justified. The geometry of the artery and plaque were generalized as the averaged stenosis level for this comparative study. Advanced heterogeneous material models, as well as hemodynamic effect were not adopted, which will change the stress distribution on the arterial wall. Despite these simplifications, the present work demonstrated that arterial stress and strain could serve as a unique index factor to predict the risk of instent restenosis. Furthermore, this work could be used to improve our understanding of the stent-artery interactions that regulate arterial mechanics and to optimize stent designs that could potentially alleviate the arterial injury and thus reduce the occurrence of restenosis.

Acknowledgment - The authors are grateful for funding from the National Science Foundation under grant No. 0926880.

\section{References}

[1] Pascual Figal DA, Valdés Chavarri M, Picó Aracil F, Pinar Bermúdez E, Iñigo García L, López Palop R, Ruipérez Abizanda JA. Usefulness of predictors of angiographic restenosis to predict clinical restenosis after coronary stent placement. Rev Esp Cardiol. 2000; 53(9):1183-8.

[2] Topol EJ. Textbook of Interventional Cardiology, 2nd ed. Eur Heart J. 1994; 15(1):147.

[3] Schwartz RS, Huber KC, Murphy JG, Edwards WD, Camrud A. R, Vlietstra RE, Holmes DR. Restenosis and the proportional neointimal response to coronary artery injury: results in a porcine model. J Am Coll Cardiol. 1992; 19(2):267-74.

[4] Rogers C, Edelman ER. Endovascular stent design dictates experimental restenosis and thrombosis. Circulation. 1995; 91(12):2995-3001.

[5] Costa MA, Simon DI. Molecular basis of restenosis and drugeluting stents. Circulation. 2005; 111(17):2257-73.

[6] Timmins LH, Miller MW, Clubb FJ, Moore JE. Increased artery wall stress post-stenting leads to greater intimal thickening. Lab Invest. 2011; 91(6):955-67. 
[7] Lally C, Dolan F, Prendergast PJ. Cardiovascular stent design and vessel stresses: A finite element analysis. J Biomech. 2005; 38(8):1574-81.

[8] Gu LX, Zhao SJ, Muttyam AK, Hammel JM. The relation between the arterial stress and restenosis rate after coronary stenting. J Med Dev. 2010; 4(3):031005.

[9] Mortier P, De Beule M, Carlier SG, Van Impe R, Verhegghe $B$, Verdonck P. Numerical study of the uniformity of balloon-expandable stent deployment. J Biomech Eng-T Asme. 2008; 130(2):021018.

[10] Zahedmanesh H, Lally C. Determination of the influence of stent strut thickness using the finite element method: Implications for vascular injury and in-stent restenosis. Med Biol Eng Comput. 2009; 47(4):385-93.

[11] Zhao SJ, Gu LX, Froemming SR. Assessment of shape memory alloy stent deployment in a stenosed artery. Biomed Eng Lett. 2011; 1:226-31.

[12] Koop K, Lootz D, Kranz C, Momma C, Becher B, Kieckbusch M. Stent material nitinol-determination of characteristics and component simulation using the finite element method. Prog Biomed Res. 2001; 6:237-45.

[13] Fischman DL, Leon MB, Baim DS, Schatz RA, Savage MP, Penn I, Detre K, Veltri L, Ricci D, Nobuyoshi M, et al. A randomized comparison of coronary-stent placement and balloon angioplasty in the treatment of coronary artery disease. Stent Restenosis Study Investigators. New Engl J Med. 1994; 331(8):496-501.

[14] FDA(P020009). Summary of safety and effectiveness data (SSED), express ${ }^{\mathrm{TM}}$ coronary stent system. Boston Scientific Scimed. 2002.

[15] Baim DS, Flatley M, Caputo R, O'Shaughnessy C, Low R, Fanelli C, Popma J, Fitzgerald P, Kuntz R. Comparison of PREdilatation vs direct stenting in coronary treatment using the Medtronic AVE S670 coronary stent system (the PREDICT trial). Am J Cardiol. 2001; 88(12):1364-9.

[16] FDA(P020047). Summary of safety and effectiveness data (SSED), multi-link vision ${ }^{\mathrm{TM}}$ coronary stent system. Guidant Corporation. 2003.
[17] FDA(P030009). Summary of safety and effectiveness data (SSED), driver ${ }^{\mathrm{TM}}$ over-the-wire stent system. Medtronic Vasc. 2003.

[18] FDA(P060001). Summary of safety and effectiveness data

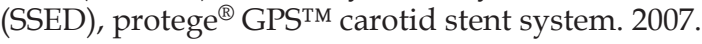

[19] Migliavacca F, Petrini L, Massarotti P, Schievano S, Auricchio F, Dubini G. Stainless and shape memory alloy coronary stents: A computational study on the interaction with the vascular wall. Biomech Model Mechanobiol. 2004; 2(4):205-17.

[20] Zhao SJ, Gu LX. Experimental study of stent conduit interactions. J. Med Dev. 2012; 6(1):017539.

[21] Kastrati A, Mehilli J, Dirschinger J, Dotzer F, Schuhlen H, Neumann FJ, Fleckenstein M, Pfafferott C, Seyfarth M, Schomig A. Intracoronary stenting and angiographic results: Strut thickness effect on restenosis outcome (ISARSTEREO) trial. Circulation. 2001; 103(23):2816-21.

[22] Pache J, Kastrati A, Mehilli J, Schuhlen H, Dotzer F, Hausleiter J, Fleckenstein M, Neumann FJ, Sattelberger U, Schmitt C, Muller M, Dirschinger J, Schomig A. Intracoronary stenting and angiographic results: Strut thickness effect on restenosis outcome (ISAR-STEREO-2) trial. J Am Coll Cardiol. 2003; 41(8):1283-8.

[23] Kitabata H, Kubo T, Komukai K, Ishibashi K, Tanimoto T, Ino Y, Takarada S, Ozaki Y, Kashiwagi M, Orii M, Shiono M, Shimamura K, Hirata K, Tanaka A, Kimura K, Mizukoshi M, Imanishi T, Akasaka T. Effect of strut thickness on neointimal atherosclerotic change over an extended follow-up period $(>/=4$ years) after bare-metal stent implantation: Intracoronary optical coherence tomography examination. Am Heart J. 2012; 163(4):608-16.

[24] Hoffmann R, Mintz GS. Coronary in-stent restenosis Predictors, treatment and prevention. Eur Heart J. 2000; 21(21):1739-49. 